\title{
Cobalt promotes angiogenesis via hypoxia-inducible factor and protects tubulointerstitium in the remnant kidney model
}

\author{
Tetsuhiro Tanaka ${ }^{1}$, Ichiro Kojima ${ }^{1}$, Takamoto Ohse ${ }^{1}$, Julie R Ingelfinger ${ }^{2}$, Stephen Adler ${ }^{3}$, \\ Toshiro Fujita ${ }^{1}$ and Masaomi Nangaku ${ }^{1}$ \\ ${ }^{1}$ Division of Nephrology and Endocrinology, University of Tokyo School of Medicine, Tokyo, Japan; ${ }^{2}$ Division \\ of Pediatric Nephrology, Massachusetts General Hospital, Boston, MA, USA and ${ }^{3}$ Department of Medicine, \\ Division of Nephrology, New York Medical College, Valhalla, NY, USA
}

\begin{abstract}
Tubulointerstitial hypoxia has been implicated in a number of progressive renal diseases, and several lines of evidence indicate that the administration of angiogenic growth factors ameliorates tubulointerstitial injury. We hypothesized that induction of hypoxia-inducible factors (HIF) mediates renoprotection by their angiogenic properties. At 5-9 weeks after subtotal nephrectomy, cobalt was administered to rats to activate HIF. Histological evaluation demonstrated that the tubulointerstitial injury was significantly ameliorated in animals that received cobalt (score: $2.51 \pm 0.12$ (cobalt) vs $3.21 \pm 0.24$ (vehicle), $P<0.05$ ). Furthermore, animals receiving cobalt had fewer vimentin- and TdT-mediated dUTP nick-end labeling (TUNEL)-positive tubular cells. The renoprotective effect of cobalt was associated with the preservation of peritubular capillary networks (rarefaction index: $13.7 \pm 0.4$ (cobalt) vs $18.6 \pm 0.9$ (vehicle), $P<0.01$ ). This improvement in capillary networks was accompanied by an increased number of proliferating (PCNA-positive) glomerular and peritubular endothelial cells. The angiogenesis produced by this method was not accompanied by an increase in vascular permeability. Furthermore, in vitro experiments clarified that HIF-1 in tubular epithelial cells promotes proliferation of endothelial cells and that HIF-2 overexpressed in renal endothelial cells mediates migration and network formation. Collectively, these findings demonstrate a renoprotective role of HIF through angiogenesis and provide a rationale for therapeutic approaches to target HIF for activation.
\end{abstract}

Laboratory Investigation (2005) 85, 1292-1307. doi:10.1038/labinvest.3700328; published online 15 August 2005

Keywords: hypoxia-inducible factor (HIF)-1; HIF-2; angiogenesis; cobalt; apoptosis

Understanding the role of chronic hypoxia in the tubulointerstitium has been a focal point for delineating the pathogenesis of progressive renal diseases. ${ }^{1-3}$ In glomerular diseases, whether immune or nonimmune in origin, the initial glomerular injury leads to capillary obstruction or microvascular insufficiency, which compromises subsequent peritubular blood flow. Hypoxia in this compartment can be a trigger for tubular epithelial cell proliferation, ${ }^{4}$ allowing cells to release a number of cytokines and growth factors, ${ }^{5}$ leading to phenotypic changes such as epithelial-mesenchymal transdifferentiation $^{6}$ and apoptosis. ${ }^{7}$ Resultant tubular atrophy or

Correspondence: Dr M Nangaku, MD, PhD, Division of Nephrology and Endocrinology, University of Tokyo School of Medicine, 7-3-1 Hongo, Bunkyo-ku, Tokyo 113-0033, Japan.

E-mail: mnangaku-tky@umin.ac.jp

Received 13 April 2005; revised 19 June 2005; accepted 21 June 2005; published online 15 August 2005 extracellular matrix (ECM) accumulation further impairs tissue oxygenation in this compartment and accelerates hypoxic injury. Consistent with these pathological sequelae, administration of angiogenic factors, such as vascular endothelial growth factor (VEGF), has been reported to ameliorate tubulointerstitial injury in some experimental models. ${ }^{8}$

Hypoxia-inducible factor (HIF), a heterodimeric transcription factor composed of $\alpha$ and $\beta$ subunits, is an important regulatory factor that allows individual cells to adapt to a hypoxic environment, ${ }^{9,10}$ and its operation is tightly regulated by the presence or absence of molecular oxygen. In normoxia, the $\alpha$ subunit is rapidly subjected to prolyl hydroxylation, ${ }^{11,12}$ binds the von Hippel-Lindau tumor suppressor protein and undergoes proteasomal degradation. In hypoxia, however, the $\alpha$ subunit escapes prolyl hydroxylation and binds the $\beta$ subunit, and the functional heterodimeric HIF then 
translocates to the nucleus and promotes angiogenesis, erythropoiesis and anaerobic metabolism through the transcriptional activation of target genes such as VEGF, erythropoietin (EPO) and glucose transporter-1. Furthermore, molecular oxygen allows hydroxylation at the conserved asparagine residue and blocks the recruitment of p300/CBP transcriptional cofactors. ${ }^{13}$ Therefore, HIF is controlled both quantitatively and qualitatively by the cellular oxygenation status.

In the kidney, HIF- $1 \alpha$ is expressed in tubular and glomerular epithelial cells, and HIF- $2 \alpha$ in glomerular and peritubular endothelial cells and peritubular fibroblasts, in response to hypoxia. ${ }^{14,15}$ From a functional aspect, an earlier study from our group demonstrated that pretreatment with cobalt ameliorated ischemic acute renal injury through the induction of HIF-regulated genes. ${ }^{16}$ However, the responsible mechanisms were not fully delineated. Furthermore, whether these findings occurred in chronic, progressive renal diseases characterized by hypoxia was unclear. Of potential clinical relevance, there remained a question of whether HIF activation by cobalt might halt or retard the progression of already existing renal injury, that is, whether cobalt administration would be potentially therapeutically useful.

In the present study, the role of HIF was investigated in the rat remnant kidney model by activating HIF and its regulated genes with repeated subcutaneous injections of cobalt. The remnant kidney is a disease model classically characterized by glomerular and systemic hypertension, but a recent study highlighted potential significance of hypoxia, which was observed at a very early stage in this condition. ${ }^{17}$ In the present study, we demonstrated that cobalt mediated significant improvement in tubulointerstitial injury as well as preservation of glomerular and peritubular capillary networks with no evidence of vascular leakage. Underlying mechanisms included proliferation of microvascular endothelial cells and reduced numbers of apoptotic tubular cells. Additionally, angiogenic properties of HIF-1 were investigated in vitro in rat proximal renal tubular epithelial cells, and those of HIF-2, in renal endothelial cells. Taken together, our observations provide a rationale for a vigorous search of means to activate $\mathrm{HIF}$ in an attempt to overcome ischemic renal diseases.

\section{Materials and methods}

\section{Animal Model}

Female Wistar rats weighing 220-250 g were used in this study. After 1 week of acclimatization, rats underwent subtotal nephrectomy (remnant kidney: RK) as follows: via a midline incision under $50 \mathrm{mg} /$ kg ketamine anesthesia, right kidney nephrectomy was performed followed by ligation of the posterior and one or two of the anterior branches of the left renal artery. Sham operation consisted of open laparotomy alone. After 1 week, animals were divided into four study groups: (1) rats without cobalt treatment, (2) rats receiving cobalt treatment at weeks $2-5,(3)$ rats receiving cobalt at weeks $6-9$, and (4) rats receiving cobalt at weeks 2-9. Cobalt chloride (Sigma, MO, USA) was dissolved to $5 \mathrm{mg} /$ $\mathrm{ml}$ in phosphate-buffered saline (PBS) and administered subcutaneously at $5 \mathrm{mg} / \mathrm{kg}$, three times a week. The subcutaneous delivery route was selected to achieve a slower cobalt delivery than the intravenous or the intraperitoneal route. No adverse effect of the cobalt subcutaneous injection was observed. At the end of week 9, rats were euthanized, and blood was taken by cardiac puncture and kidneys removed for histological evaluation. Equal induction of the disease was confirmed by comparing blood urea nitrogen (BUN) levels at week 1 among the groups (shown in Table 1). In this study, cobalt was used to activate HIF on the basis that cobalt inhibits prolyl hydroxylation of the HIF- $\alpha$ subunit, an initial step of E3 ubiquitination, and stabilizes HIF- $\alpha$, irrespective of the oxygenation status. ${ }^{18}$

In a separate set of experiments, rats were injected with $60 \mathrm{mg} / \mathrm{kg}$ pimonidazole (Chemicon, CA, USA), a chemical adduct that detects tissue hypoxia, via tail vein $2 \mathrm{~h}$ prior to killing and kidneys were processed for immunodetection of hypoxic tubular cells.

BUN and serum creatinine levels were measured at week 1, 5 and 9 using a commercial kit (Wako, Osaka, Japan). Urine samples were collected in metabolic cages at designated time points and urinary protein excretion was measured using a Bio-Rad assay reagent (Bio-Rad, CA, USA). Blood pressure (BP) was measured by an occlusive tail-cuff plethysmograph attached to a pneumatic pulse transducer. Rats were conditioned carefully at least three times on separate days before the first measurement. BP was recorded as the mean value of three separate measurements obtained at each session.

\section{Histological Evaluation}

Methyl-Carnoy's-fixed, paraffin-embedded sections $(3 \mu \mathrm{M})$ were dewaxed and rehydrated through graded alcohols. Periodic Acid-Schiff (PAS) staining was used for the semiquantitative evaluation of glomerular sclerosis and tubulointerstitial injury. Glomerular sclerosis was quantified per glomerulus as follows: grade 0 , no sclerosis; grade $1,<25 \%$; grade $2,<50 \%$; grade $3,<75 \%$; and grade $4, \geq 75 \%$ involved. At least 30 glomeruli were evaluated under $\times 400$ magnification and averaged. Tubulointerstitial injury score was evaluated based on morphological changes of the tubules such as dilatation, distortion of tubular basement membranes and atrophy as follows: grade 0, no 
Table 1 Physical and biological data of experimental animals

\begin{tabular}{|c|c|c|c|c|c|}
\hline & \multicolumn{5}{|c|}{ Group } \\
\hline & \multirow{2}{*}{$\begin{array}{l}\text { Sham } \\
\mathrm{n}=4\end{array}$} & \multicolumn{4}{|c|}{ Remnant kidney } \\
\hline & & $\begin{array}{c}\text { Co }(-) \\
\mathrm{n}=6\end{array}$ & $\begin{array}{c}\text { Co (weeks 2-5) } \\
\mathrm{n}=4\end{array}$ & $\begin{array}{c}\text { Co (weeks 6-9) } \\
\mathrm{n}=8\end{array}$ & $\begin{array}{c}\text { Co (weeks 2-9) } \\
\mathrm{n}=4\end{array}$ \\
\hline \multicolumn{6}{|l|}{$B W(g)$} \\
\hline Week 9 & N/A & $290 \pm 15$ & $285 \pm 18$ & $274 \pm 11$ & $286 \pm 10$ \\
\hline \multicolumn{6}{|c|}{ SBP (mmHg) } \\
\hline Week 9 & $106 \pm 17$ & $158 \pm 4(* *)$ & $151 \pm 2(* *)$ & $149 \pm 11(* *)$ & $156 \pm 7(* *)$ \\
\hline \multicolumn{6}{|c|}{$B U N(\mathrm{mg} / \mathrm{dl})$} \\
\hline Week 1 & N/A & $35.0 \pm 7.2$ & $33.5 \pm 14.7$ & $34.0 \pm 6.4$ & $32.3 \pm 3.7$ \\
\hline Week 5 & N/A & $39.8 \pm 14.0$ & $34.9 \pm 2.2$ & $35.2 \pm 8.3$ & $29.7 \pm 1.2$ \\
\hline Week 9 & $19.0 \pm 2.1$ & $61.9 \pm 10.6\left(^{* *}\right)$ & $41.0 \pm 5.5\left({ }^{* *}\right)\left({ }^{\# \#}\right)$ & $34.4 \pm 6.4\left({ }^{* *}\right)(\# \#)$ & $40.1 \pm 6.3\left({ }^{* *}\right)(\#)$ \\
\hline \multicolumn{6}{|c|}{ Cre $(\mathrm{mg} / \mathrm{dl})$} \\
\hline Week 5 & N/A & $1.14 \pm 0.10$ & $1.14 \pm 0.19$ & $1.17 \pm 0.07$ & $1.02 \pm 0.10$ \\
\hline Week 9 & $0.51 \pm 0.03$ & $1.37 \pm 0.21\left(^{* *}\right)$ & $1.34 \pm 0.23\left(^{* *}\right)$ & $1.13 \pm 0.16(* *)\left({ }^{\#}\right)$ & $1.02 \pm 0.19\left({ }^{* *}\right)(\# \#)$ \\
\hline \multicolumn{6}{|c|}{ U-Protein (mg/day) } \\
\hline Week 1 & N/A & $5.5 \pm 4.2$ & $5.4 \pm 5.1$ & $2.2 \pm 1.1$ & $4.2 \pm 2.8$ \\
\hline Week 5 & N/A & $43.4 \pm 40.6$ & $4.5 \pm 0.3$ & $34.3 \pm 33.1$ & $11.1 \pm 7.1$ \\
\hline Week 9 & $2.8 \pm 0.4$ & $172.6 \pm 92.2(* *)$ & $134.3 \pm 92.9(* *)$ & $56.2 \pm 34.6\left(^{* *}\right)\left({ }^{\# \#)}\right.$ & $83.4 \pm 17.0\left({ }^{* *}\right)(\#)$ \\
\hline
\end{tabular}

Three different periods of cobalt administration were tested to determine the optimal time point of the treatment.

$\mathrm{N} / \mathrm{A}=$ not available.

$\left({ }^{* *}\right): P<0.01$ vs sham.

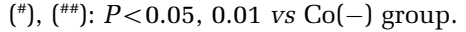

morphological deformities; grade $1,<10 \%$; grade 2 , $<25 \%$; grade $3,<50 \%$; grade $4,<75 \%$; and grade 5 , $\geq 75 \%$ involved. More than 20 consecutive fields were examined under $\times 400$ magnification and averaged per slide.

\section{Immunohistochemistry}

Immunostaining was conducted by a conventional indirect immunoperoxidase method. Glomerular and peritubular capillaries were identified with JG12 antibody, raised against aminopeptidase $\mathrm{P}$ of microvascular endothelial cells (1/100, Bender MedSystems, San Bruno, CA, USA). Antigens were retrieved by autoclaving samples at $121^{\circ} \mathrm{C}$ for $20 \mathrm{~min}$ in $10 \mathrm{mM}$ citrate buffer $(\mathrm{pH}$ 6.0). Subsequently, they were probed with JG12, biotinylated anti-mouse IgG (1/400, Vector, CA, USA) and HRPavidin (1/1000, Vector). Color development was made with nickel, $\mathrm{H}_{2} \mathrm{O}_{2}$ and DAB (Wako) to yield black staining.

Proliferating capillary endothelial cells were detected by double staining with JG12 and antiPCNA antibodies (1/500, DAKO, Carpinteria, CA, USA). After antigen retrieval, sections were first probed with JG12 as described above, except that anti-mouse IgG1 (1/200, Santa-Cruz biochemistry, CA, USA) was used as the secondary antibody. Then, after quenching remaining peroxidase activity with $3 \% \mathrm{H}_{2} \mathrm{O}_{2} / \mathrm{PBS}$ for $10 \mathrm{~min}$, slides were incubated with anti-PCNA, biotinylated anti-mouse IgG2a (1/200, Santa-Cruz biochemistry) and HRPavidin. Color was developed with $\mathrm{H}_{2} \mathrm{O}_{2}$ and DAB, to yield brown staining. The number of JG12-positive PCNA-positive cells was averaged per 10 glomeruli or per $0.25 \mathrm{~mm}^{2}$ area.

Immunodetection for other proteins included utilization of Hypoxyprobe ${ }^{\mathrm{TM}}-1 \mathrm{Mb} 1(1 / 200$, Chemicon), anti-vimentin (1/500, DAKO), anti-VEGF (1/ 100, Santa-Cruz biochemistry) and anti-ED-1 (which recognizes an antigen expressed by the majority of tissue macrophages: 1/40, Cymbus biotechnology, Chandlers Ford, Hants, UK) antibodies.

\section{Evaluation of Capillaries}

The number of glomerular capillaries was counted under $\times 400$ magnification in 30 consecutive glomeruli and averaged. Density of peritubular capillaries was quantified using a rarefaction index, as described previously. ${ }^{19}$ Using $10 \times 10$ grids under $\times 200$ magnification, squares without JG12-positive capillaries were counted, and the proportion of squares not containing capillaries was calculated. Using this method, the minimal possible rarefaction index is 0 , which indicates that every square contains JG12-positive endothelia, while the maximum possible score is 100 , in which no positive staining is identified. 
TdT-Mediated dUTP Nick-End Labeling (TUNEL) Staining

Apoptotic cells were detected by TUNEL staining. Buffered-formalin-fixed sections were processed with cytonin (15 min at room temperature). After quenching of endogenous peroxidase $\left(3 \% \mathrm{H}_{2} \mathrm{O}_{2}\right.$ in methanol, $5 \mathrm{~min}$ ), sections were reacted with terminal deoxynucleotidyl transferase (TdT) and biotinylated dUTP in TdT reaction buffer $(30 \mathrm{mM}$ Tris-HCl, pH 7.2, $140 \mathrm{mM}$ sodium cacodylate, $1 \mathrm{mM}$ $\mathrm{Mn}^{2+}$ ), for $60 \mathrm{~min}$ at $37^{\circ} \mathrm{C}$. Biotinylated nuclei were detected using $\mathrm{HRP}$-avidin, $\mathrm{H}_{2} \mathrm{O}_{2}$ and DAB. The number of TUNEL-positive tubular cells were counted in 20 nonoverlapping cortical fields under $\times 200$ magnification and averaged.

\section{Evaluation of Vascular Permeability}

Vascular permeability changes were evaluated by Evans blue dye extravasation test. ${ }^{20}$ Cobalt- or vehicle-treated rats were injected with $20 \mathrm{mg} / \mathrm{kg}$ Evans blue via tail vein. After 20 min, kidneys were removed and the cortex dissected. The Evans blue dye was extracted from the tissue with formamide, and the concentration was measured by obtaining optic absorbance at $630 \mathrm{~nm}$ using a microtiter plate reader. The Evans blue dye content was corrected for dry tissue weight.

\section{Real-Time PCR}

RNA was isolated from the renal cortex using ISOGEN (Nippon Gene, Tokyo, Japan) and reverse transcribed with Im-Prom II reverse transcription kit (Promega, WI, USA). A measure of one-twentieth (vol/vol) cDNA was used as a template for subsequent quantification. PCR was run on an iCycler (Bio-Rad), using iQ ${ }^{\mathrm{TM}}$ SYBR Green PCR supermix (Bio-Rad). The relative amount of HIF-regulated genes was calculated and corrected for that of $\beta$-actin. Target genes included EPO, VEGF and Tie2. Corresponding primers have been described in our previous publication, ${ }^{16}$ except for Tie2 (fw: 5'-CTGAGAACAACATAGGATCAAGCAA-3'; rv: 5' TTTCCCCCTCCAAGGTCTTT-3').

\section{Cell Culture}

A kidney vascular endothelial cell line, GEN, derived from glomerular endothelial cells was used and is called 'kidney endothelial cell line' elsewhere in this paper. Endothelial cells were cultured in RPMI 1640 medium containing 10\% fetal bovine serum (FBS, JRH biosciences, KS, USA) and 10\% NuSerum (BD biosciences, MA, USA). ${ }^{21}$ Immortalized rat proximal tubular cells (IRPTC) were grown in DMEM supplemented with 5\% FBS, buffered with 25 mM HEPES. ${ }^{22}$ Cells were maintained at $37^{\circ} \mathrm{C}$ under humidified $5 \% \quad \mathrm{CO}_{2}$. Hypoxic conditions were provided by exposure of cells to $1 \% \mathrm{O}_{2}$ in a multigas incubator, APM-30D (ASTEC, Fukuoka, Japan).

To explore the specific role of HIF-1 in tubular epithelial cells, IRPTC clones that express a dominant-negative (dn) HIF- $1 \alpha^{23}$ were used. These IRPTC clones have been established and characterized in detail in our previous study. ${ }^{7}$ Although dnHIF- $1 \alpha$ interferes with both HIF isoforms, HIF-1 rather than HIH-2 is the dominant HIF in ITPTC cells (unpublished observation). Functional analyses of HIF-2 in renal endothelial cells were carried out by establishing clones that overexpress $\mathrm{HIF}-2 \alpha$. An open-reading frame encoding full-length mouse HIF-2 $\alpha$ was generated by PCR using fw: 5'-TCGGAGGGCCACG GCGACAATGACAG-3' and rv: 5'-AAGTGAAGCTG GCAGGTCAAGACGGC-3' primers and cDNA of C57BL6 mouse kidney as a template, with the annealing/extension step set at $65^{\circ} \mathrm{C}, 180 \mathrm{~s}$. Amplified fragments were subcloned to pCR2.1 (Invitrogen, CA, USA) and expressed in pcDNA3.1(-) (pmHIF-2 $\alpha /$ pcDNA, Invitrogen). Nucleotide sequences were confirmed by dideoxy DNA sequencing. Endothelial clones overexpressing HIF- $2 \alpha$ were generated by transfection of pmHIF-2 $\alpha /$ pcDNA using cationic liposome (Lipofectamine: Invitrogen). After transfection, clones were selected with $600 \mu \mathrm{g} /$ ml G418 (Sigma) and outgrowths of cells carrying the vector were isolated using cloning cylinders. Two independent clones (\#3 and \#7) were analyzed in this study.

\section{Immunoblotting}

Protein was extracted from control endothelial cells and HIF-2 $\alpha$ clones using 1\% NP-40 lysis buffer $(150 \mathrm{mM}$ sodium chloride, 1\% NP-40, $50 \mathrm{mM}$ Tris-HCl, pH 8.0). Aliquots of cellular protein were resolved by $7.5 \%$ SDS-PAGE under reducing conditions and transferred onto PVDF membranes (Amersham, NJ, USA). Primary antibody raised against mouse $\mathrm{HIF}-2 \alpha$ was used at $1 / 3000$ (PM9, a gift from Dr Michael $S$ Wiesener, University of Erlangen-Nuremberg, Germany). Specific bands for HIF-2 $\alpha$ were visualized with AP-conjugated secondary antibody and BCIP/NBT (Sigma).

\section{Preparation of Conditioned Media (CM)}

Angiogenic properties that renal tubular HIF-1 confers on endothelial cells were examined by preparing the CM. ${ }^{24}$ Control IRPTC and dnHIF-1 $\alpha$ clones were grown to confluence in $100 \mathrm{~mm}$ culture dishes, medium was changed to RPMI 1640 without FBS and the cells were then cultured under normoxic or hypoxic conditions for another $24 \mathrm{~h}$. Supernatants were then collected, centrifuged to remove cellular debris and passed through $0.22 \mu \mathrm{m}$ pore filters (Millipore, Tokyo, Japan). 


\section{Cultured Endothelial Cell Proliferation Assay}

Endothelial proliferation in the CM was examined by 3-(4,5-dimethylthiazol-2-yl)-5-(3-carboxymethoxyphenyl)-2-(4-sulfophenyl)-2H-tetrazolium (MTS) reduction to formazan (MTS assay: Promega, WI, USA) and bromodeoxyuridine (BrdU) incorporation into chromosomal DNA (Amersham). ${ }^{25,26}$ Cells were seeded at $1.0 \times 10^{4}$ (MTS assay) or $2.0 \times 10^{4}$ (BrdU incorporation) on 96-well culture plates and incubated overnight. Then, the medium was aspirated and replaced by the CM, and cells were incubated for another $24 \mathrm{~h}$. After the incubation, cells were loaded with either MTS reagent or BrdU, and the cell proliferation was measured using a microtiter plate reader, as indicated by the supplier.

\section{Endothelial Cell Migration and Capillary Network Formation}

Endothelial migration assays were conducted using a modified Boyden chamber $^{27}$ (Beckton Dickinson, NJ, USA). Control cells or clones overexpressing HIF- $2 \alpha$ were suspended at $1.0 \times 10^{5} / 200 \mu \mathrm{l}$ RPMI containing 1\% FBS and seeded on the upper chamber precoated with $0.1 \%$ gelatin $(8 \mu \mathrm{m}$ pores, 24-well plate format). The insert was then placed in wells containing $700 \mu \mathrm{l}$ RPMI fully supplemented with serum, and cells were incubated for $24 \mathrm{~h}$ in either normoxic or hypoxic conditions. Cells migrating to the bottom of the chamber were fixed with methanol and visualized with Giemsa staining. The number of migrating cells was counted under a microscope.

Capillary network formation was examined by Matrigel assays (BD biosciences, MA, USA). Control cells or HIF-2 $\alpha$ clones were seeded on four-well LabTek chamber slides (Nalge Nunc International, IL, USA) coated with Matrigel and cultured in normoxia or hypoxia for the indicated periods. After incubation, the formation of capillary networks was observed with a phase-contrast microscope and quantitatively evaluated by measuring capillary tube length.

\section{Statistical Analyses}

Data are expressed as mean \pm s.e.m., unless otherwise noted. Statistical analyses were carried out using a Stat-View software (Ver. 5.0 SAS Institute, Cary, NC, USA). Comparisons among groups were made using ANOVA, with the correction of Bonferroni/Dunn's method. Nonparametric data were analyzed with the Mann-Whitney test. $P$-values of $<0.05$ were considered statistically significant.

\section{Results}

\section{Tubulointerstitial Hypoxia in the Remnant Kidney}

In our previous study, evidence of hypoxia was observed in cortical tubular cells in the early stage of the rat remnant kidney. ${ }^{17}$ However, some controversy remains as to whether hypoxia is still present in the advanced stages of this model. ${ }^{28,29}$ In this regard, pimonidazole staining was conducted to visualize hypoxia at week 9 of the remnant kidney (Figure 1). In areas with moderate damage, hypoxic areas appeared to extend from the outer medulla to the inner cortex (b), as compared to controls (a), while in regions with severe injury, hypoxic signals were evident in dilated, proximal tubules (c). These results confirm the presence of hypoxia in the advanced stage of the remnant kidney, which warrant the present investigation.

\section{Determination of the Administration Period of Cobalt (A Pilot Study)}

To optimize the time point for cobalt treatment, a pilot study was carried out (Table 1). Rats were categorized into five groups: (0) sham-operated rats, (1) RK rats without cobalt treatment (vehicle), (2) RK rats receiving cobalt in the first half of the study period (weeks 2-5), (3) RK rats receiving cobalt in the latter half of the study period (weeks 6-9) and (4) RK rats receiving cobalt throughout the entire period (weeks 2-9). Body weight (BW), systolic BP (SBP),
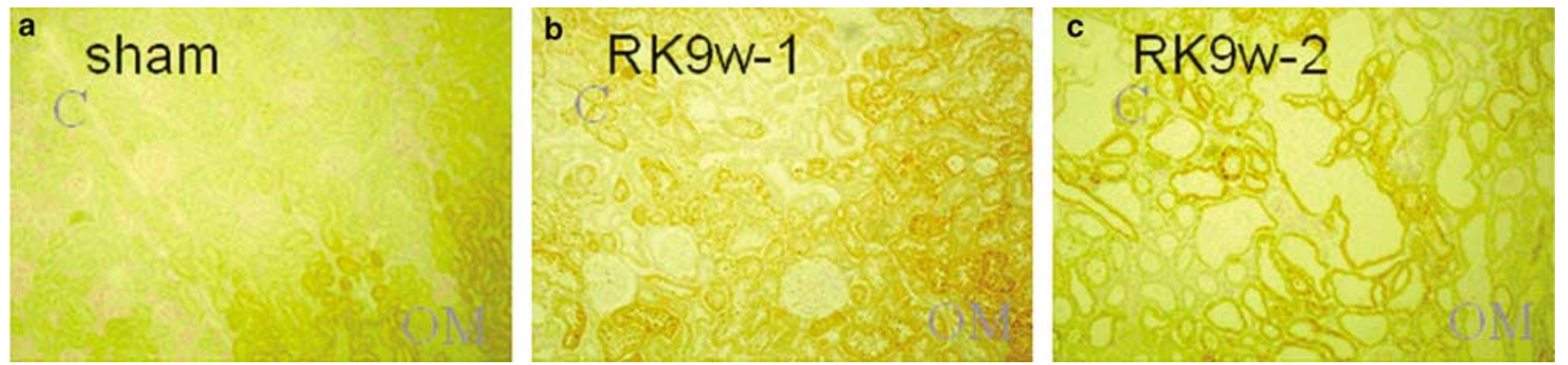

Figure 1 Hypoxia in the remnant kidney. Pimonidazole staining identified hypoxic tubules in the remnant kidney at week 9. In areas where injury was moderate, the hypoxic areas extended from the outer medulla to the cortex (b). In the severely damaged cortex, the hypoxic signal was observed in dilated tubules (c). In the cortex of sham-operated rats, there was no positive staining (a). Original magnification: $\times 100$. Abbreviations: C, cortex; OM, outer medulla. 
BUN, serum creatinine levels and urinary protein excretion were measured at given time points. Among rats receiving subtotal nephrectomy (groups 1-4), there was no difference in BW and SBP throughout the experimental course. At week 9, BUN levels were lower in rats in groups 2, 3 and 4. Serum creatinine levels and urinary protein excretion were also significantly reduced in groups 3 and 4. There was no significant difference in these parameters between groups 3 and 4 . Based on these preliminary results, the effect of HIF was investigated in detail by administering cobalt at weeks 5-9.
Cobalt administration alone in sham-operated rats (for 4 and 8 weeks) did not affect these parameters (data not shown).

\section{Activation of HIF and Induction of HIF-Regulated Genes by Cobalt}

Activation of HIF by cobalt was confirmed by immunodetection of the transgene in 'hypoxiaresponsive element (HRE)-luciferase' transgenic rats developed recently in our laboratory ${ }^{28}$ (Figure 2a). a
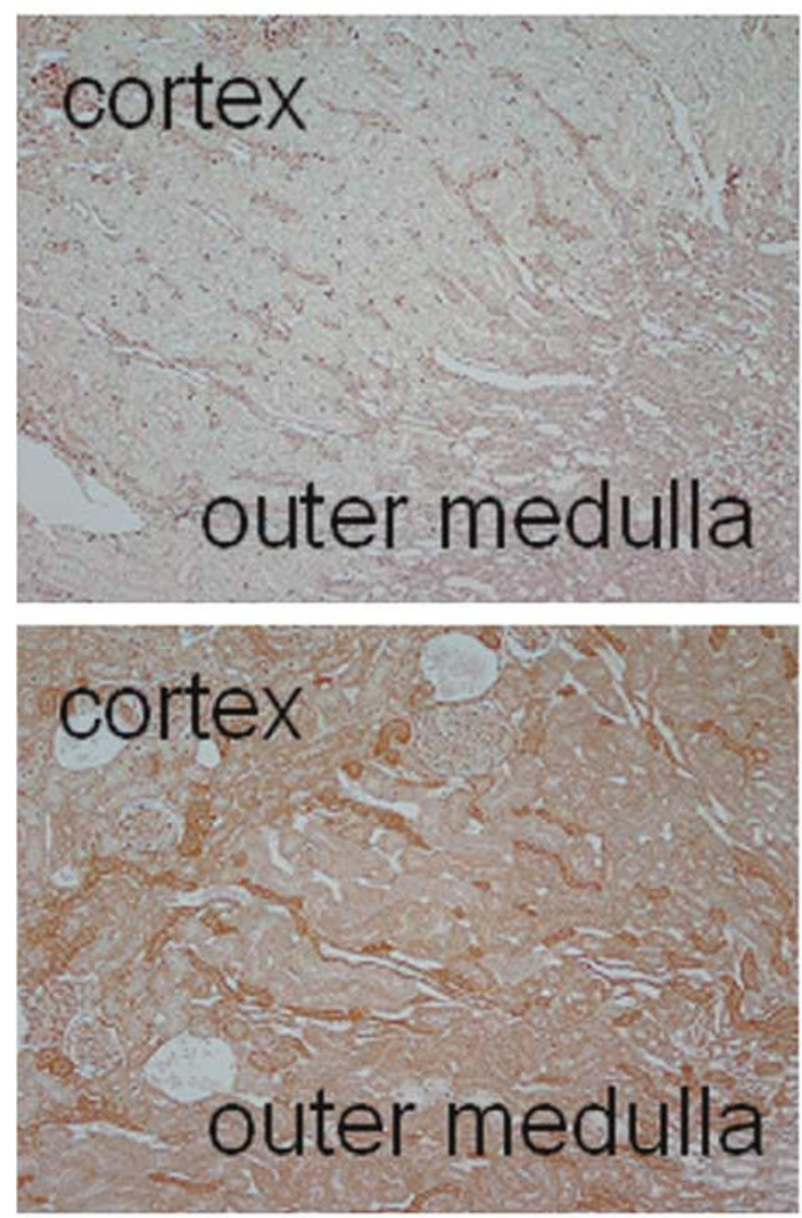

b
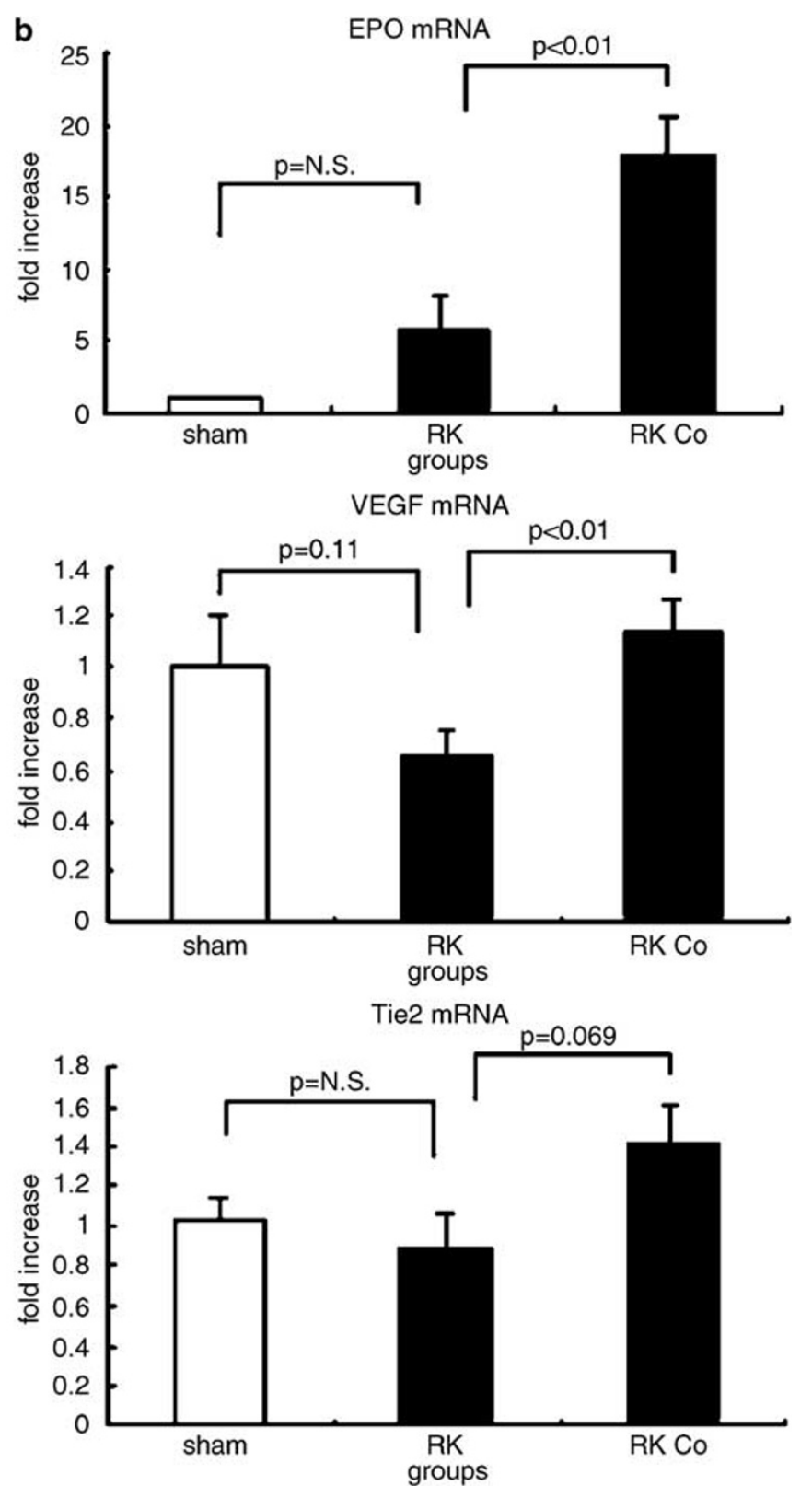

Figure 2 Activation of HIF and induction of HIF-regulated genes by cobalt. Cobalt was administered to 'HRE-luciferase' transgenic rats for 4 weeks and kidneys were immunoprobed for the transgene (a). The transgene expression was stronger in all areas of the kidney in cobalt-treated rats than in vehicle-treated controls. In addition, renal transcripts of HIF-regulated genes were quantified by real-time PCR $(n=4-8)$. (b) Cobalt administration increased EPO, VEGF and Tie2 mRNA expression. Note also that VEGF mRNA, an angiogenic factor, decreased in the RK group ( 0.66 -fold, $P=0.11 \mathrm{vs}$ sham) and was restored rather than overexpressed by cobalt (1.14-fold). The baseline expression levels of EPO, VEGF and Tie2 mRNA in the sham group were arbitrarily set at 1. 
These animals are transgenic rats harboring FLAG-tagged luciferase reporter under the control of HRE. Therefore, the detection of the transgene serves as direct measure of HIF activation. In cobalttreated rats, the transgene signal was obviously stronger than in those of control rats, in all areas of the kidney. Induction of HIF-1- and HIF-2-regulated genes was quantified by real-time PCR analysis (Figure 2b). At week 9, the amount of EPO and VEGF mRNA significantly increased from $5.8 \pm$ 2.3- and $0.66 \pm 0.10$-fold to $18.0 \pm 2.6$ - and $1.14 \pm 0.12$ fold (both $P<0.01$ vs vehicle) by cobalt. Furthermore, the amount of Tie2 mRNA tended to be higher in the cobalt-treated group $(0.90 \pm 0.16$ - and $1.42 \pm 0.19$-fold $(P=0.069))$.

Additionally, rats treated with cobalt had roughened and uneven skin, and furless areas, such as the ears, were erythematous (not shown). These skin phenotypes are similar to those observed in HIF-1 $\alpha$ overexpressing mice described previously. ${ }^{30}$

\section{Cobalt Treatment Ameliorates Tubulointerstitial Injury in the Remnant Kidney}

Representative PAS stainings of sham-operated (sham), vehicle-treated remnant (RK) and cobalttreated remnant (RK-Co) kidneys are shown (Figure 3a-c). In the glomeruli, focal changes showing mesangial expansion and sclerosis were observed to a similar degree in the RK and RK-Co groups (score $2.43 \pm 0.08$ vs $2.36 \pm 0.12$, NS, Figure $3 g$ ). In the cortical tubulointerstitium, however, foci of tubular atrophy, dilatation and interstitial fibrosis were less severe in the RK-Co group than in the RK group (score $3.21 \pm 0.24$ vs $2.51 \pm 0.12, P<0.05$,
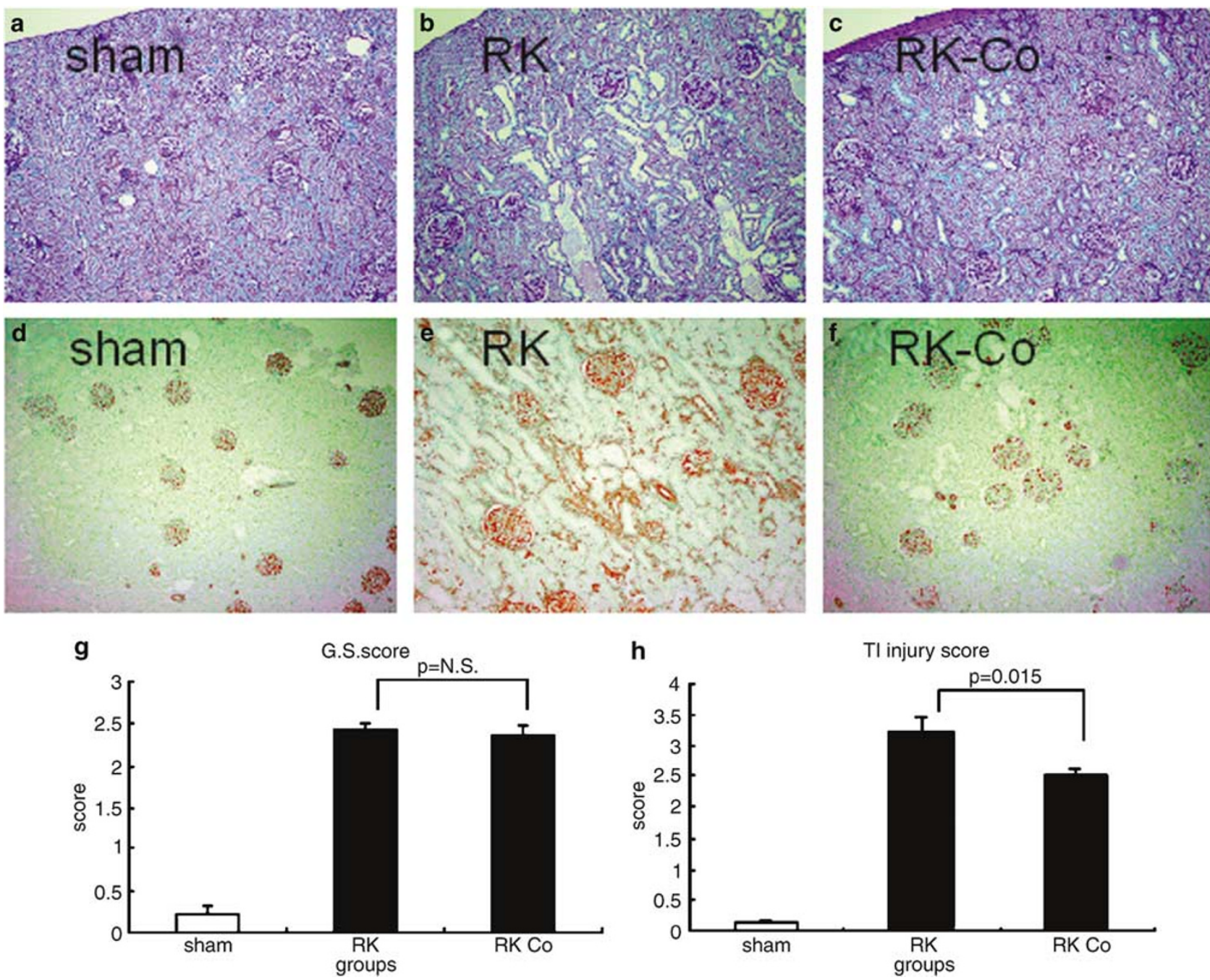

Figure 3 Histological improvements by cobalt. PAS staining clarified that the tubulointerstitial injury, such as dilatation and atrophy, was markedly ameliorated by cobalt treatment, while glomerular injury was not improved (a-c). Semiquantitative scoring of glomerular sclerosis and tubulointerstitial injury was summarized in $(\mathbf{g}-\mathbf{h})$. Tubulointerstitial vimentin staining was also less severe in the RK-Co group (d-f). Original magnification: $\times 100$. 
Figure 3h). Amelioration of tubular injury was also corroborated by immunostaining with vimentin, a marker of dedifferentiation and tubular injury (Figure 3d-f).

\section{Glomerular and Peritubular Capillary Networks}

Considering that cobalt and HIF activation led to significant histological improvement in the remnant kidney, underlying mechanisms were investigated focusing on glomerular and peritubular capillary networks (Figures 4 and 5). Microscopic views of kidneys in each group are shown in Figure 4a-c. In the glomeruli of the RK group, the number of JG12positive capillaries decreased from $42.0 \pm 2.6$ (sham) to $30.9 \pm 2.3$ (RK). Cobalt treatment restored the number to $39.2 \pm 2.7 \quad(P<0.05$ vs the RK group; Figure $4 \mathrm{~d}-\mathrm{f}$ and quantified in Figure 5a). The tubulointerstitial capillary density was quantified by measuring the rarefaction index. The index significantly decreased from $18.6 \pm 0.9$ to $13.7 \pm 0.4$ $(P<0.01$ vs the RK group; Figure $4 \mathrm{~g}-\mathrm{i}$ and quantified in Figure 5b), indicating that the tubulointerstitial capillary density was restored by cobalt. The reconstitution of peritubular vascular networks occurred at the microvessel level, because there was no obvious difference in the number of $\alpha$-SMApositive vessels between the RK and RK-Co groups (data not shown).

To address the question of whether the preservation of microvasculature was associated with proliferation of vascular endothelial cells, double staining with JG12 and anti-PCNA antibodies was performed and the number of double-positive cells was counted in both glomeruli (Figure 5c) and tubulointerstitium (Figure 5d). With cobalt treatment, the number of proliferating endothelial cells increased from $1.21 \pm 0.23$ to $2.34 \pm 0.36$ in the glomeruli $(P<0.01)$ and from $1.21 \pm 0.10$ to $2.03 \pm$ 0.29 in the tubulointerstitium $(P<0.05)$. These results indicate that the retention of capillary
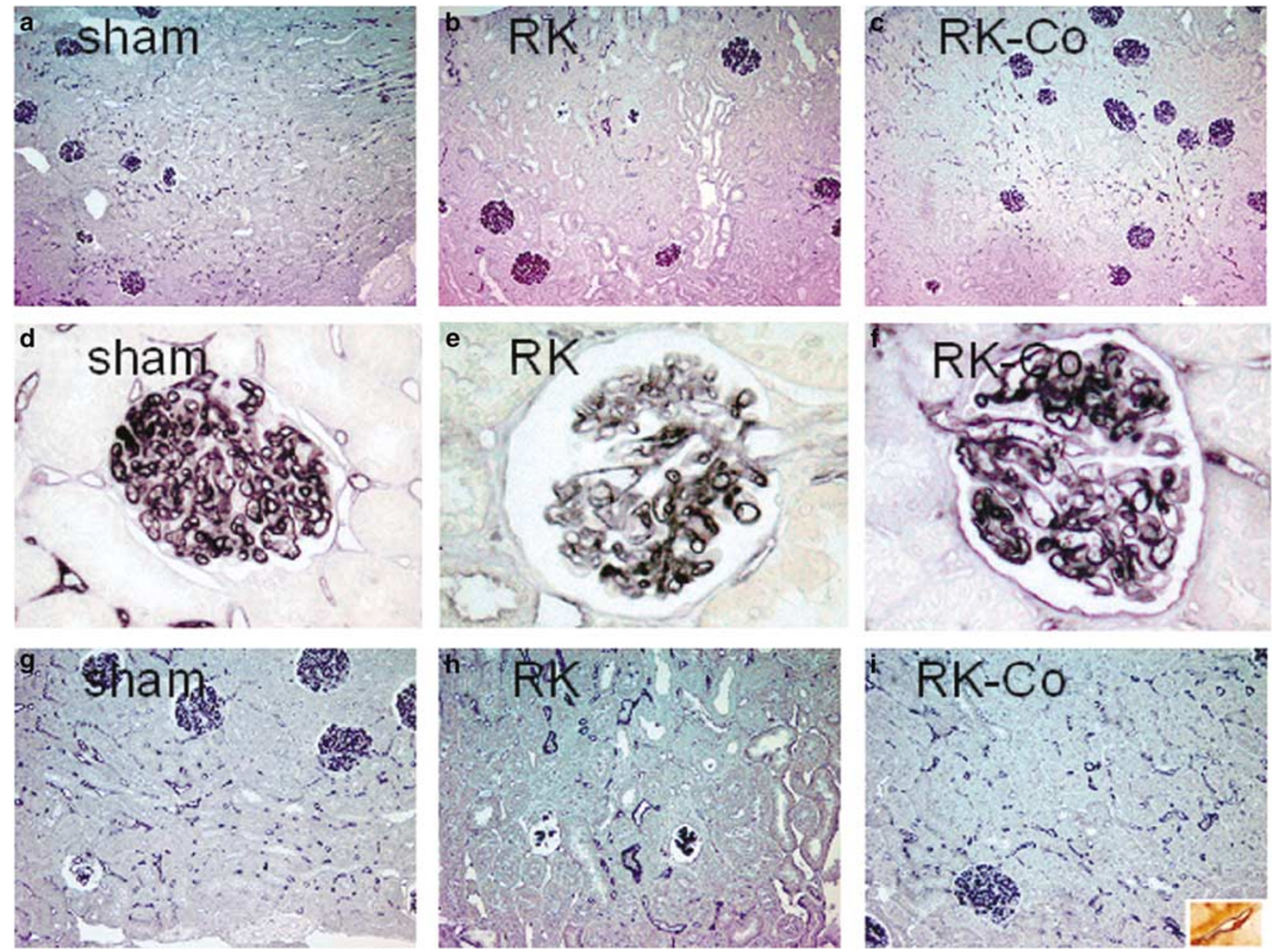

Figure 4 Changes in glomerular and peritubular capillary networks. Glomerular and peritubular capillaries were analyzed immunohistochemically by JG12 staining. Progressive loss of both glomerular and peritubular capillaries was observed in the remnant kidney, which was reversed by cobalt treatment $(\mathbf{a}-\mathbf{c})$. Representative, magnified views in glomeruli (d-f) and tubulointerstitium (g-i) are also shown. A picture of proliferating endothelial cells is presented in the inset (lower right of (i)). Original magnification: $\times 100(\mathbf{a}-\mathbf{c})$, $\times 400(\mathbf{d}-\mathbf{f})$ and $\times 200(\mathrm{~g}-\mathbf{i})$. 
a

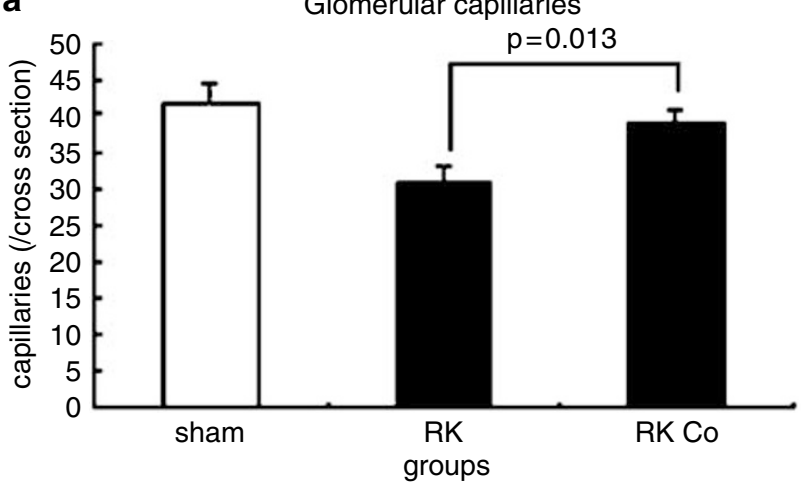

C

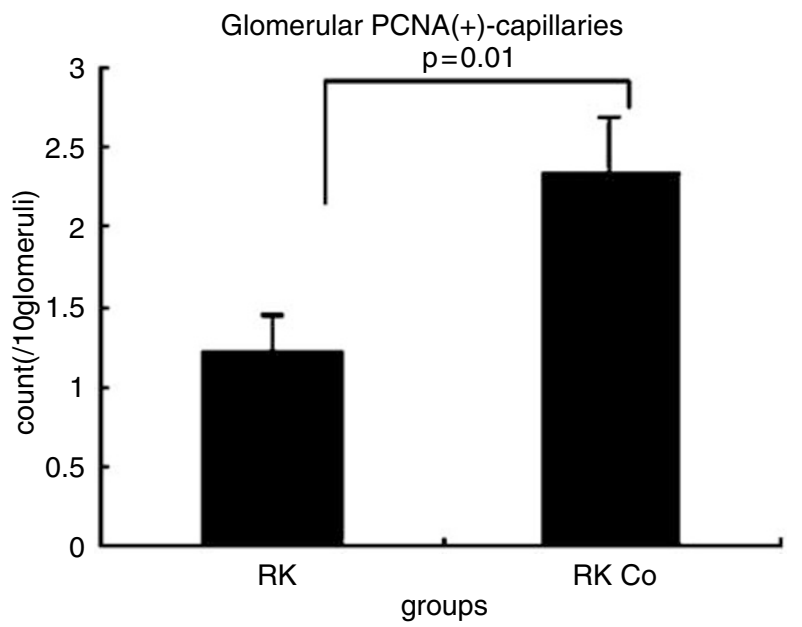

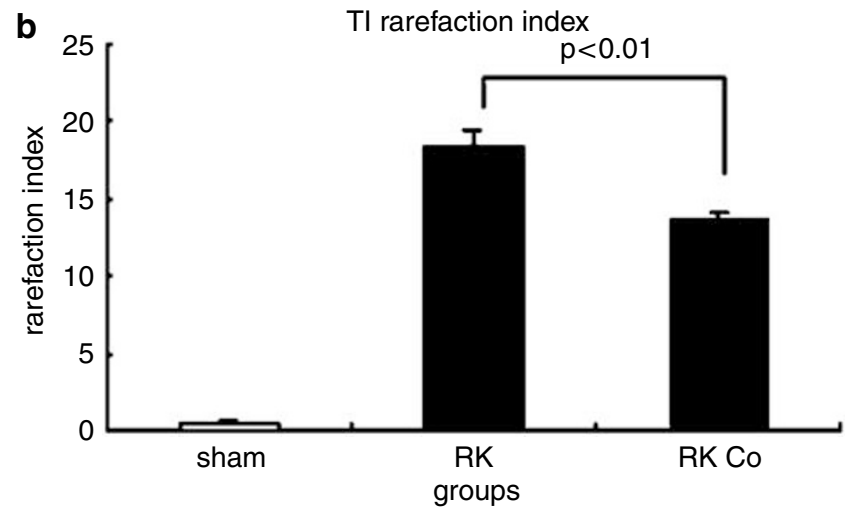

d

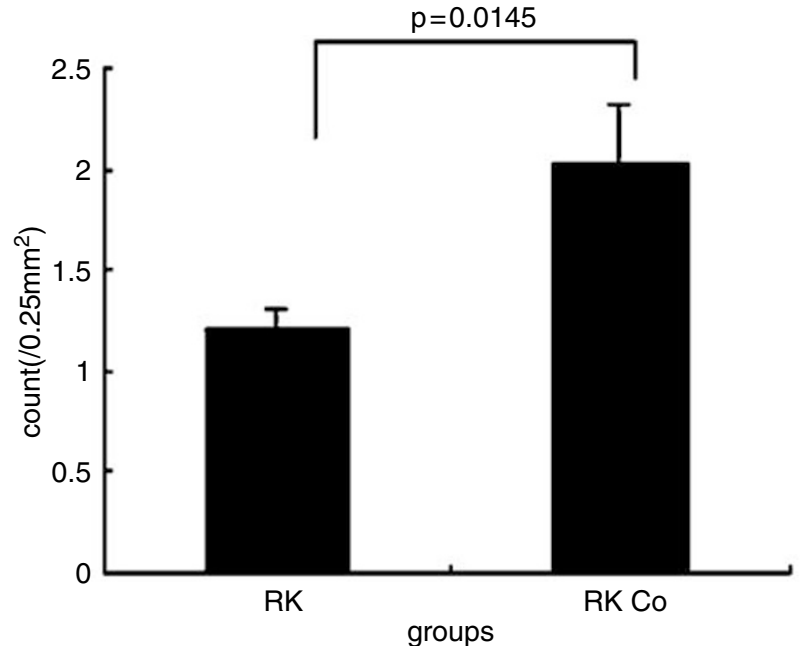

Figure 5 Quantification of capillaries and proliferating vascular endothelial cells. The number of glomerular capillaries (a) and the rarefaction of peritubular capillaries (b) were quantified. In the glomeruli, the decrease in the number of JG12-positive capillaries was restored by cobalt treatment. Likewise, the rarefaction index, an indicator of peritubular vascular density, was improved by cobalt. Proliferating glomerular or peritubular endothelial cells were identified by double staining with JG12 and anti-PCNA antibodies. The number of double-positive cells increased in both glomeruli and tubulointerstitium (c-d).

networks in both glomeruli and tubulointerstitium was accompanied by the proliferation of vascular endothelial cells.

Endothelial proliferation and reconstruction of peritubular capillary networks were associated with the restoration of VEGF immunostaining in tubules located in the outer stripe of the outer medulla (Figure 6). In the sham kidneys, VEGF staining in the tubulointerstitium was most evident in the outer medulla (Figure 6a), which decreased markedly in the RK group (Figure 6b). By cobalt administration, VEGF staining in these areas became apparently restored (Figure 6c), in keeping with our previous quantification of VEGF mRNA (Figure 2b).

The capillary networks in cobalt-treated animals revealed no increase in vascular permeability, as assessed by Evans blue dye content in the cortex of the kidney (Figure 6d). The baseline content of Evans blue was $65.8 \pm 10.1 \mathrm{ng} / \mathrm{mg}$ dry tissue. In the remnant kidney, the dye content was
$120.2 \pm 13.3 \mathrm{ng} / \mathrm{mg}$ in the RK group and $122.7 \pm$ $13.7 \mathrm{ng} / \mathrm{mg}$ in the RK-Co group, respectively.

\section{Cobalt Treatment Protects Tubular Cells from Apoptosis and Inhibits Macrophage Infiltration}

The renoprotective effect of cobalt was associated with a reduced number of apoptotic tubular cells and infiltrating macrophages (Figure 7). In the cortex, the number of TUNEL-positive tubular cells appeared to be less in the RK-Co group (Figure 7c, $2.5 \pm 0.4$ per $\times 200$ field) than in the RK group (Figure 7b, 5.1 $\pm 0.3, \quad P<0.01$; Figure $7 \mathrm{a}-\mathrm{C}$ and quantified in Figure $7 \mathrm{~g}$ ). The number of ED-1positive infiltrating macrophages was also counted in the cortical tubulointerstitium and was significantly less in the RK-Co group $(26.3 \pm 2.5$ per $\times 200$ field) than in the RK group $(44.8 \pm 4.6, P<0.01$; Figure $7 \mathrm{~d}-\mathrm{f}$ and quantified in Figure $7 \mathrm{~h}$ ). 



Figure 6 VEGF immunostaining and testing of vascular permeability. Improvement of renal microvasculature was associated with restoration of VEGF expression in the outer medulla. In sham-operated kidneys, VEGF-staining was most evident in the outer medulla (a). In the remnant kidney, however, the expression faded substantially, in parallel with progressive loss of peritubular capillaries (b). Administration of cobalt restored expression of VEGF in these areas (c). Leakage/permeability of newly formed vessels was examined by measuring the Evans blue dye content (d). In the remnant kidney, the dye content in vehicle-treated and cobalt-treated rat kidneys revealed no difference, indicating that the newly constructed vasculature by cobalt was not leakage prone. (a-c) Original magnification $\times 100$ and (d) $n=3-4$ in each group.

\section{HIF-1 in Tubular Epithelial Cells Modulates Endothelial Proliferation In Vitro}

Endothelial proliferation by systemic HIF activation was further analyzed by in vitro experiments, focusing on the role of HIF-1 in neighboring tubular epithelial cells and that of HIF-2 in renal endothelial cells. These different cell types and HIF-2 isoforms were selected based on previous in vivo observations on HIF- $\alpha$ isoform expression. ${ }^{14,28}$

To test whether HIF-1 in tubular epithelial cells modulates endothelial cell proliferation, CM were prepared from normoxic or hypoxic, control and dnHIF-1 $\alpha$ IRPTC (Figure 8). Incubation of cultured endothelial cells with the CM from normoxic culture revealed no difference in proliferation. However, when the CM were obtained from hypoxic IRPTC clones, endothelial cell growth showed a clear difference according to the origin of IRPTC clones (control or dnHIF-1 $\alpha$ ). Use of the CM obtained from hypoxic dnHIF- $1 \alpha$ clones resulted in the impairment of endothelial growth as compared to those from hypoxic control IRPTC. Similar results were obtained in both MTS (a) and BrdU incorporation (b) assays. The difference in endothelial proliferation indicates that HIF-1 in renal tubules either promotes the release of angiogenic factors or inhibits the secretion of angiostatic substances in response to hypoxia.

\section{HIF-2 in Renal Endothelial Cells Mediates Migration and Network Formation In Vitro}

To test further whether HIF-2 in renal endothelial cells contributes to capillary formation in a hypoxic milieu, clones that stably overexpress HIF-2 $\alpha$ were established and tested for migration and network formation. Immunoblotting shows that stable transfectants express higher levels of HIF- $2 \alpha$ in both normoxia and hypoxia (Figure 9a). These clones showed similar growth in monolayer culture, as compared to control endothelial cells (Figure 9b). Hypoxia tended to promote cell proliferation at $24 \mathrm{~h}$ and retard growth at $72 \mathrm{~h}$ in these clones, neither of which reached statistical significance.

Endothelial migration was evaluated using the modified Boyden chamber (Figure 9c). When control cells were incubated in hypoxia for $24 \mathrm{~h}$, a larger number of migrating endothelial cells were observed as compared to normoxic control cells. Endothelial migration was then compared among control cells and two HIF- $2 \alpha$ clones (\#3 and \#7) under conditions of hypoxia. The number of migrating cells was 

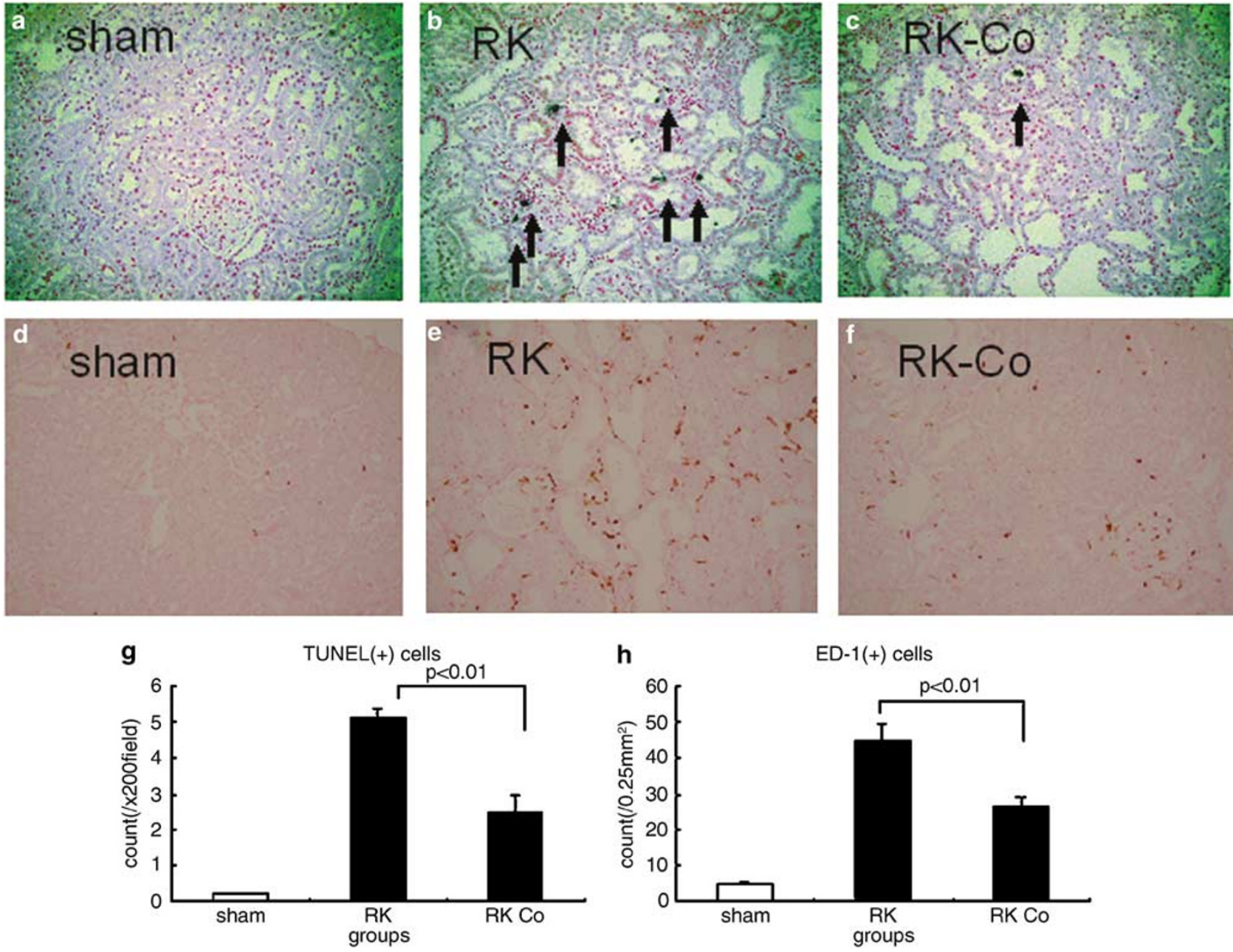

Figure 7 TUNEL and ED-1 staining. The renoprotective effect of cobalt was also associated with the reduced number of apoptotic tubular cells and infiltrating macrophages in the cortical tubulointerstitium. In TUNEL staining, the number of apoptosis (arrows) was markedly reduced by cobalt treatment (a-c) quantified in (g); counting: per $\times 200$ field, $P<0.01$ ). The number of infiltrating macrophages was also reduced in the cobalt-treated group (d-f, quantified in (h); counting: per $\times 200$ field).

significantly larger in two HIF-2 $\alpha$ clones than in control endothelial cells, suggesting the involvement of HIF-2 in endothelial migration. Cell migration in HIF- $2 \alpha$ clones tended to be more evident even under normoxic culture conditions. Capillary network formation was further evaluated in these clones (Figure 10). When cells were seeded onto Matrigel at subconfluent density, all three clones showed the appearance of tube-like structures at $4-5 \mathrm{~h}$, which was more prominent in hypoxia (Figure 10b compared to a), and even more evident in HIF-2 $\alpha$ clones (Figure 10c). Capillary network formation was quantified by measuring the tube length at $24 \mathrm{~h}$ (Figure 10e). Hypoxia alone promoted capillary network formation in control endothelial cells, in keeping with previous observations, ${ }^{31}$ and overexpression of HIF- $2 \alpha$ promoted network formation even more significantly. Likewise, vascular sprouting, which was also detectable at $4-5 \mathrm{~h}$ after seeding, was more prominent in HIF-2 $\alpha$ clones (Figure 10d). These findings further imply that HIF-2 in renal endothelial cells contributes to the construction of capillary networks.

\section{Discussion}

This study demonstrates the roles of cobalt- and HIF-mediated angiogenesis in the ischemic tubulointerstitium in late phases of the rat remnant kidney. Administration of cobalt led to the activation of HIF, induced a number of HIF-regulated genes and ameliorated tubulointerstitial injury in this model, which was associated with proliferation of microvascular endothelial cells and preserved capillary networks in both glomeruli and tubulointerstitium. Angiogenic properties of tubular epithelial HIF-1 and endothelial HIF-2 seen in vivo were further validated in vitro. In addition, cobalt treatment rendered cortical tubular cells resistant to apoptosis. 
a

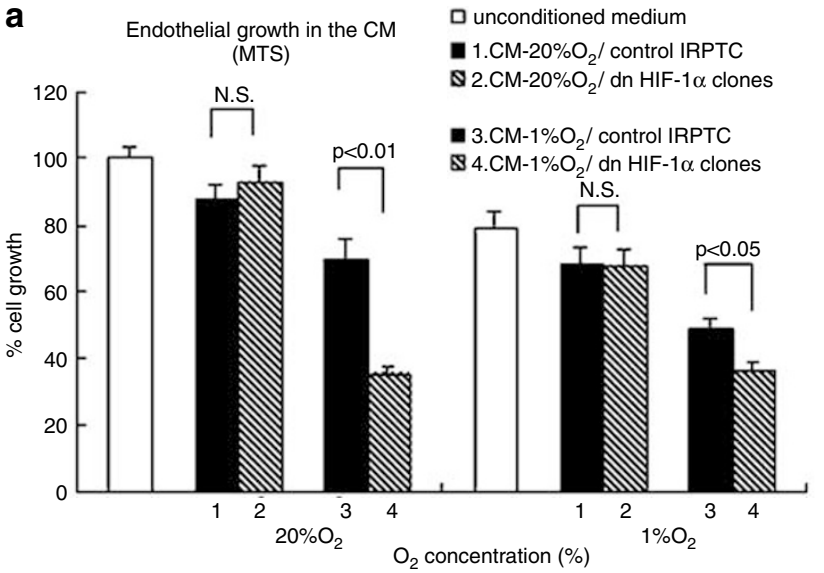

b



Figure 8 Endothelial proliferation in the CM from IRPTC. Cultured renal endothelial cells were incubated in the conditioned media (CM) obtained from (1) normoxic control IRPTC clone, (2) normoxic dnHIF-1 $\alpha$ clone, (3) hypoxic control IRPTC clone and (4) hypoxic dnHIF-1 $\alpha$ clone cultured for $24 \mathrm{~h}$. When endothelial cells were cultured in the CM obtained from normoxic IRPTC (control (1) and dnHIF-1 $\alpha$ (2) clones), there was no difference in the growth rate. Upon incubation with the CM from hypoxic IRPTC ((3) and (4)), however, a significant difference in cell growth was observed. By abrogating the tubular function of HIF-1, the endothelial growth in the CM became significantly impaired. Similar results were obtained irrespective of the oxygen concentration during the culture of endothelial cells. These findings were confirmed by both MTS (a) and BrdU incorporation (b) assays (representative of more than three independent experiments, $n=8$ ).

HIF regulates a variety of genes essential to cellular adaptation to hypoxia. Among them are a number of angiogenic and vasoactive genes such as VEGF and nitric oxide (NO) synthase. However, it seems to depend on the types of cells and experimental conditions whether HIF-1 mediates angiogenesis, according to previous tumor xenograft studies.

In the kidney, defining the role of angiogenesis is important for understanding the pathogenesis of renal damage and for developing a new therapeutic approach, because it has been established from a comprehensive human pathological analysis that a

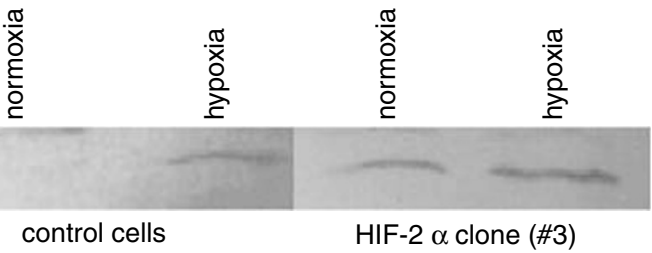

b

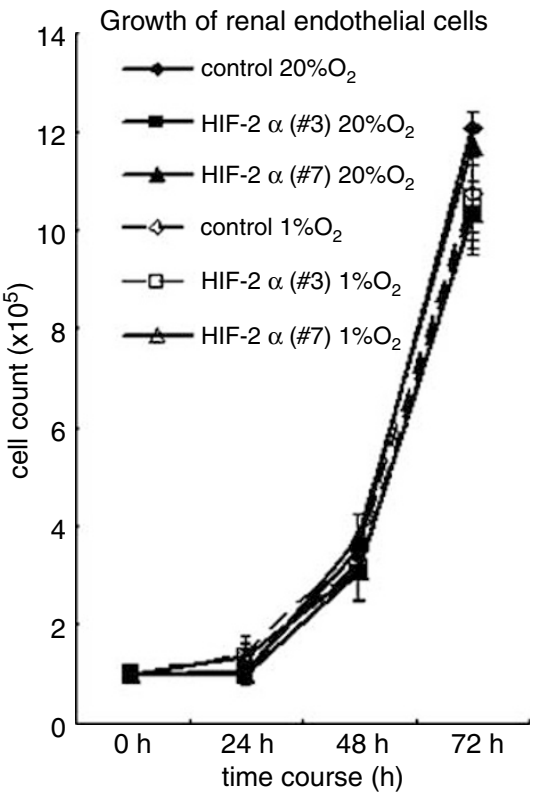

C



Figure 9 Overexpression of HIF-2 $\alpha$ promotes migration in renal endothelial cells. Endothelial clones that overexpress HIF- $2 \alpha$ were established and the expression levels were analyzed by immunoblotting (a). Stable transfectants show stronger expression of HIF-2 $\alpha$ in both normoxia and hypoxia. Cell growth was checked in the monolayer cell culture (b). Control cells and HIF$2 \alpha$ clones (\#3 and \#7) were seeded at $1.0 \times 10^{5}$ per six-well plate and cultured in either normoxia or hypoxia for up to $72 \mathrm{~h}$. There was no difference in growth among these clones in the monolayer culture system. The endothelial cell migration was then quantified using a modified Boyden chamber (c). Control cells and HIF$2 \alpha$ clones were seeded on the upper chamber and incubated in normoxia or hypoxia for $24 \mathrm{~h}$. In control cells, the number of migrating cells was significantly larger in hypoxia than in normoxia. In addition, the cell migration was more evident in clones overexpressing HIF- $2 \alpha$ than in control cells, under hypoxic conditions. Similar trends were obtained even under normoxic conditions $(n=4)$.

damage and destruction of peritubular capillaries are associated with the fall in residual renal function. ${ }^{32}$ Furthermore, the experimental adminis- 

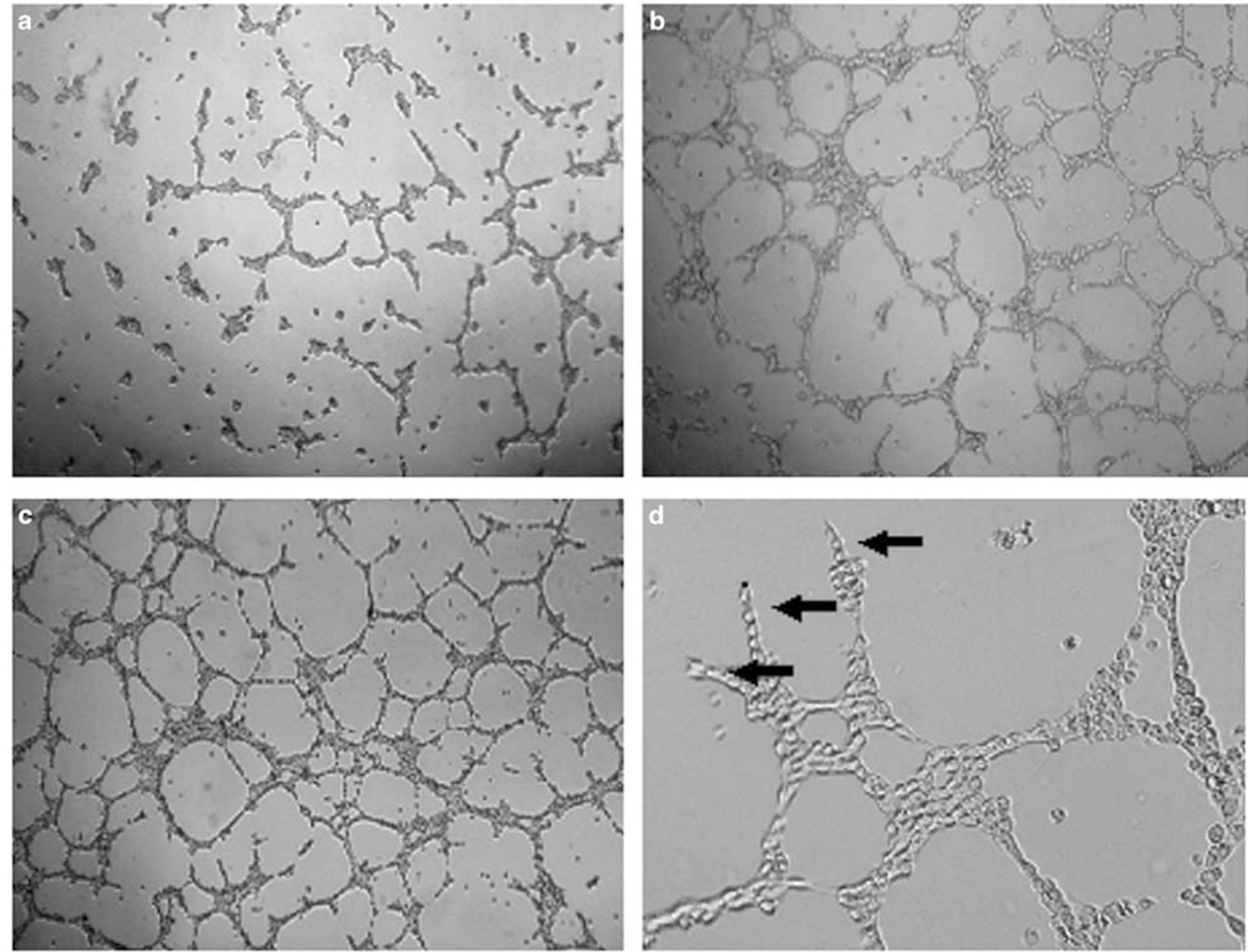

e

Tube length of renal endothelial cells

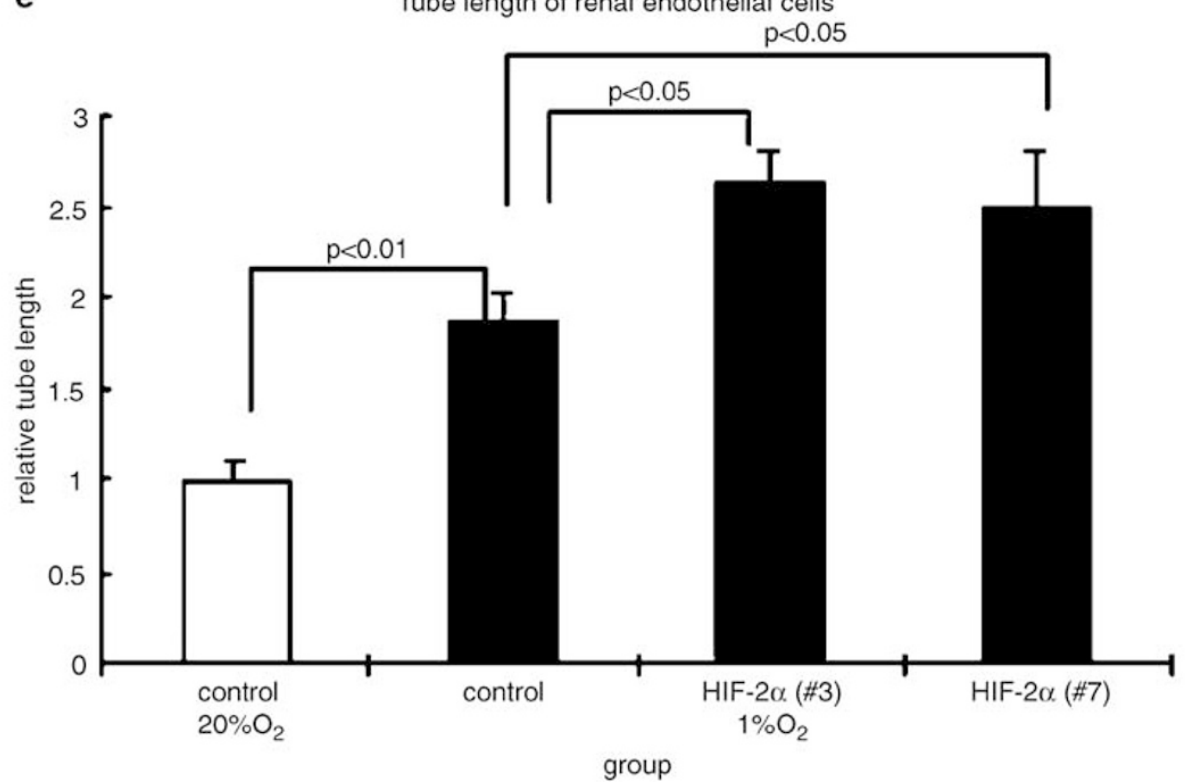

Figure 10 Capillary network formation. Cells seeded on Matrigel formed capillary-like structure at approximately $4-5 \mathrm{~h}$, which was more prominent in hypoxia (b) as compared to normoxia (a). When HIF-2 $\alpha$ clone was cultured in hypoxia (c), network formation was even more evident than hypoxic, control endothelial cells. A magnified view (d) shows representative vascular sprouting (arrows), which was larger in number in order of $(\mathbf{c})>(\mathbf{b})>(\mathbf{a})$. The capillary network formation on the Matrigel was enumerated after $24 \mathrm{~h}$ of hypoxic incubation by measuring the length of capillary structures (e). Hypoxia alone promoted network formation, which became even more evident by overexpressing HIF-2 $\alpha$. The average tube length in normoxic, control endothelial cells was arbitrarily set at 1 . Original magnification: $\times 40(\mathbf{a}-\mathbf{c})$ and $\times 100(\mathbf{d}), n=3$. 
tration of vasoactive factors, such as VEGF and NO, has been shown to be renoprotective in a variety of glomerular diseases, ${ }^{33,34}$ including the remnant kidney model, ${ }^{35}$ in which intrinsic VEGF expression decreases at later stages. ${ }^{19}$ Based on these previous observations, it appears likely that the induction of angiogenesis by cobalt and HIF activation contributed greatly, if not entirely, to the amelioration of tubulointerstitial injury in this model. To our knowledge, this is the first demonstration that activation of HIF can promote angiogenesis and protect tubulointerstitial injury in the remnant kidney. Successful induction of angiogenesis by overexpressing HIF-1 $\alpha$ has been reported in other systemic organs such as the heart ${ }^{36}$ and the hind limb. ${ }^{37}$

Anatomically, the newly constructed vascular networks in the tubulointerstitium appeared patchy, suggesting that the increase in vascularity occurred at the level of microvessels. The number of vessels in cobalt-treated kidneys that expressed $\alpha$-SMA was comparable to those in the vehicle-treated kidneys (not shown), consistent with a previous report concerning the heart. ${ }^{38}$

It is important to note that the new vessels did not show any evidence of vascular leakage. Evans blue content in the remnant kidney revealed no difference between vehicle- and Co-treated RK groups, nor was there any significant difference observed when kidneys were subjected to ischemia-reperfusion injury, a disease model characterized by interstitial edema in its early stage (not shown). These results suggest that these new vessels are not prone to leakage, possibly because cobalt treatment leads to a more coordinated angiogenesis as compared to that seen when a single angiogenic substance downstream of HIF, such as VEGF is used. Given the experimental results of vascular hyperpermeability in mice overexpressing VEGF in the $\operatorname{skin}^{39}$ and clinical observations of tissue edema when VEGF is administered in peripheral arterial diseases ${ }^{40}$ angiogenesis by HIF may be a new and promising target for therapeutic approaches in ischemic renal diseases.

Angiogenic properties of HIF were further verified in vitro. Our studies indicate that HIF-1 in tubular epithelial cells either releases angiogenic factors or inhibits the secretion of angiostatic substances, because the CM obtained from hypoxic dnHIF-1 $\alpha$ IRPTC obviously retarded the growth of renal endothelial cells as compared to media from control IRPTC. These observations are consistent with in vivo findings that cobalt restored immunostaining of VEGF, an HIF-regulated angiogenic factor, in the outer medulla. Looking at the data together, it is tempting to speculate that tubular epithelial cells release angiogenic substances in response to hypoxia in vivo, as is the case for podocytes. ${ }^{41}$ On the other hand, overexpression of HIF- $2 \alpha$ in cultured renal endothelial cells resulted in accelerated migration and capillary network formation in response to hypoxia. To date, several studies using HIF-2 $\alpha$ knockout mice revealed divergent properties, including impairment in remodeling of the primary vascular networks at postvasculogenesis stages. ${ }^{42}$ Further studies will be needed to clarify the role of HIF-2 in renal pathology. There is a good possibility, however, that HIF-2 serves a renoprotective role, considering that HIF-2 regulates gene expression of endothelial receptors for angiogenic factors such as Tie2 ${ }^{43,44}$ and VEGFR-2 (Flk-1/KDR). ${ }^{45,46}$

The renoprotective effect of cobalt was also associated with the reduced number of apoptotic cortical tubular cells. The role of HIF-1 on the survival of epithelial cells is obviously multifactorial, ${ }^{47}$ but overall it promotes cell survival by mediating cellular adaptation to hypoxia. Both EPO and VEGF, which are induced by HIF, have been shown to protect renal tubular cells from apoptosis, ${ }^{48,49}$ which may have contributed to the antiapoptotic effect of HIF demonstrated in the remnant kidney.

In contrast to the obvious renoprotection in the tubulointerstitium, the current protocol failed to protect glomeruli from sclerosis, despite the significantly increased number of glomerular capillaries in the cobalt treatment group. This may partly be explained by glomerular and systemic hypertension that has been linked with glomerular sclerosis in this model. ${ }^{50,51}$

A significant reduction in proteinuria was demonstrated by cobalt, despite no histological improvement in glomerular histological analysis. However, there remains a possibility that certain factors mediated by cobalt contributed to the maintenance of glomerular structures at levels below microscopic examination. VEGF is one of the candidates, because blockade of circulating VEGF by neutralizing antibodies induces proteinuria, ${ }^{52}$ in association with glomerular endothelial cell detachment and hypertrophy, and a significant decrease in nephrin, a crucial component of glomerular slit diaphragm. In addition, podocytespecific heterozygous deletion for VEGF-A results in proteinuria and endotheliosis. VEGF also serves as an autocrine survival factor in human podocytes in vitro. ${ }^{53}$ Based on these findings, it is tempting to speculate that the decrease in VEGF in this model may have caused endothelial/podocyte injury, while supplementation of VEGF through HIF led to the maintenance of glomerular structures and the reduction of proteinuria.

In summary, the present findings provide evidence of angiogenesis by cobalt and demonstrate a renoprotective role of HIF in the rat remnant kidney. Given the observations that the degree of tubulointerstitial injury correlates with renal insufficiency ${ }^{54}$ and that the damage in this compartment is correlated with loss of peritubular capillaries, ${ }^{32}$ angiogenesis through activation of HIF is a promising therapeutic target against progressive, hypoxic renal diseases. In this sense, modalities that activate 
HIF, including methods to inhibit prolyl-hydroxylase activities, ${ }^{55,56}$ should be eagerly pursued.

\section{Acknowledgements}

This study was partially supported by research grants from the Japanese Society of Internal Medicine and the Pharmaceuticals and Medical Devices Agency (Japan) and was funded by the Grant-in-Aid for Scientific Research from Japan Society for the Promotion of Science (Grants 17390246).

\section{References}

1 Eckardt KU, Rosenberger C, Jurgensen JS, et al. Role of hypoxia in the pathogenesis of renal disease. Blood Purif 2003;21:253-257.

2 Fine LG, Bandyopadhay D, Norman JT. Is there a common mechanism for the progression of different types of renal diseases other than proteinuria? Towards the unifying theme of chronic hypoxia. Kidney Int Suppl 2000;75:S22-26.

3 Nangaku M. Hypoxia and tubulointerstitial injury: a final common pathway to end-stage renal failure. Nephron Exp Nephrol 2004;98:e8-e12.

4 Sahai A, Mei C, Schrier RW, et al. Mechanisms of chronic hypoxia-induced renal cell growth. Kidney Int 1999;56:1277-1281.

5 Orphanides C, Fine LG, Norman JT. Hypoxia stimulates proximal tubular cell matrix production via a TGF-beta1-independent mechanism. Kidney Int 1997; 52:637-647.

6 Manotham K, Tanaka T, Matsumoto M, et al. Transdifferentiation of cultured tubular cells induced by hypoxia. Kidney Int 2004;65:871-880.

7 Tanaka T, Hanafusa N, Ingelfinger JR, et al. Hypoxia induces apoptosis in SV40-immortalized rat proximal tubular cells through the mitochondrial pathways, devoid of HIF1-mediated upregulation of Bax. Biochem Biophys Res Commun 2003;309:222-231.

8 Kang DH, Kanellis J, Hugo C, et al. Role of the microvascular endothelium in progressive renal disease. J Am Soc Nephrol 2002;13:806-816.

9 Huang LE, Bunn HF. Hypoxia-inducible factor and its biomedical relevance. J Biol Chem 2003;278: 19575-19578

10 Wenger RH. Cellular adaptation to hypoxia: $\mathrm{O}_{2}$-sensing protein hydroxylases, hypoxia-inducible transcription factors, and $\mathrm{O}_{2}$-regulated gene expression. FASEB J 2002;16:1151-1162.

11 Ivan M, Kondo K, Yang H, et al. HIFalpha targeted for VHL-mediated destruction by proline hydroxylation: implications for $\mathrm{O}_{2}$ sensing. Science 2001;292: 464-468.

12 Jaakkola P, Mole DR, Tian YM, et al. Targeting of HIF-alpha to the von Hippel-Lindau ubiquitylation complex by $\mathrm{O}_{2}$-regulated prolyl hydroxylation. Science 2001;292:468-472.

13 Lando D, Peet DJ, Whelan DA, et al. Asparagine hydroxylation of the HIF transactivation domain a hypoxic switch. Science 2002;295:858-861.

14 Rosenberger C, Mandriota S, Jurgensen JS, et al. Expression of hypoxia-inducible factor-1alpha and -2alpha in hypoxic and ischemic rat kidneys. J Am Soc Nephrol 2002;13:1721-1732.

15 Rosenberger C, Griethe W, Gruber G, et al. Cellular responses to hypoxia after renal segmental infarction. Kidney Int 2003;64:874-886.

16 Matsumoto M, Makino Y, Tanaka T, et al. Induction of renoprotective gene expression by cobalt ameliorates ischemic injury of the kidney in rats. J Am Soc Nephrol 2003;14:1825-1832.

17 Manotham K, Tanaka T, Matsumoto M, et al. Evidence of tubular hypoxia in the early phase in the remnant kidney model. J Am Soc Nephrol 2004;15:1277-1288.

18 Epstein AC, Gleadle JM, McNeill LA, et al. C. elegans EGL-9 and mammalian homologs define a family of dioxygenases that regulate HIF by prolyl hydroxylation. Cell 2001;107:43-54.

19 Kang DH, Hughes J, Mazzali M, et al. Impaired angiogenesis in the remnant kidney model: II. Vascular endothelial growth factor administration reduces renal fibrosis and stabilizes renal function. J Am Soc Nephrol 2001;12:1448-1457.

20 Saldanha JC, Gargiulo DL, Silva SS, et al. A model of chronic IgE-mediated food allergy in ovalbuminsensitized mice. Braz J Med Biol Res 2004;37: 809-816.

21 Adler S, Eng B. Integrin receptors and function on cultured glomerular endothelial cells. Kidney Int 1993;44:278-284.

22 Ingelfinger JR, Jung F, Diamant D, et al. Rat proximal tubule cell line transformed with origin-defective SV40 DNA: autocrine ANG II feedback. Am J Physiol 1999;276:F218-F227.

23 Halterman MW, Miller CC, Federoff HJ. Hypoxiainducible factor-1alpha mediates hypoxia-induced delayed neuronal death that involves p53. J Neurosci 1999;19:6818-6824.

24 Sakuda H, Nakashima Y, Kuriyama S, et al. Media conditioned by smooth muscle cells cultured in a variety of hypoxic environments stimulates in vitro angiogenesis. A relationship to transforming growth factor-beta 1. Am J Pathol 1992;141:1507-1516.

25 Hanafusa N, Yatomi Y, Yamada K, et al. Sphingosine 1-phosphate stimulates rat mesangial cell proliferation from outside the cells. Nephrol Dial Transplant 2002;17:580-586.

26 Tanaka T, Nangaku M, Miyata T, et al. Blockade of calcium influx through L-type calcium channels attenuates mitochondrial injury and apoptosis in hypoxic renal tubular cells. J Am Soc Nephrol 2004;15: 2320-2333.

27 Nagata D, Mogi M, Walsh K. AMP-activated protein kinase (AMPK) signaling in endothelial cells is essential for angiogenesis in response to hypoxic stress. J Biol Chem 2003;278:31000-31006.

28 Tanaka T, Miyata T, Inagi R, et al. Hypoxia in renal disease with proteinuria and/or glomerular hypertension. Am J Pathol 2004;165:1979-1992.

29 Priyadarshi A, Periyasamy S, Burke TJ, et al. Effects of reduction of renal mass on renal oxygen tension and erythropoietin production in the rat. Kidney Int 2002;61:542-546.

30 Elson DA, Thurston G, Huang LE, et al. Induction of hypervascularity without leakage or inflammation in transgenic mice overexpressing hypoxia-inducible factor-1alpha. Genes Dev 2001;15:2520-2532.

31 Phillips PG, Birnby LM, Narendran A. Hypoxia induces capillary network formation in cultured 
bovine pulmonary microvessel endothelial cells. Am J Physiol 1995;268:L789-L800.

32 Bohle A, Mackensen-Haen S, Wehrmann M. Significance of postglomerular capillaries in the pathogenesis of chronic renal failure. Kidney Blood Press Res 1996;19:191-195.

33 Kim YG, Suga SI, Kang DH, et al. Vascular endothelial growth factor accelerates renal recovery in experimental thrombotic microangiopathy. Kidney Int 2000;58: 2390-2399.

34 Suga S, Kim YG, Joly A, et al. Vascular endothelial growth factor (VEGF121) protects rats from renal infarction in thrombotic microangiopathy. Kidney Int 2001;60:1297-1308.

35 Kang DH, Nakagawa T, Feng L, et al. Nitric oxide modulates vascular disease in the remnant kidney model. Am J Pathol 2002;161:239-248.

36 Shyu KG, Wang MT, Wang BW, et al. Intramyocardial injection of naked DNA encoding HIF-1alpha/VP16 hybrid to enhance angiogenesis in an acute myocardial infarction model in the rat. Cardiovasc Res 2002;54: 576-583.

37 Vincent KA, Shyu KG, Luo Y, et al. Angiogenesis is induced in a rabbit model of hindlimb ischemia by naked DNA encoding an HIF-1alpha/VP16 hybrid transcription factor. Circulation 2000;102:2255-2261.

38 Huang Y, Hickey RP, Yeh JL, et al. Cardiac myocytespecific HIF-1alpha deletion alters vascularization, energy availability, calcium flux, and contractility in the normoxic heart. FASEB J 2004;18:1138-1140.

39 Larcher F, Murillas R, Bolontrade M, et al. VEGF/VPF overexpression in skin of transgenic mice induces angiogenesis, vascular hyperpermeability and accelerated tumor development. Oncogene 1998;17:303-311.

40 Rissanen TT, Rutanen J, Yla-Herttuala S. Gene transfer for therapeutic vascular growth in myocardial and peripheral ischemia. Adv Genet 2004;52:117-164.

41 Eremina V, Quaggin SE. The role of VEGF-A in glomerular development and function. Curr Opin Nephrol Hypertens 2004;13:9-15.

42 Peng J, Zhang L, Drysdale L, et al. The transcription factor EPAS-1/hypoxia-inducible factor 2alpha plays an important role in vascular remodeling. Proc Natl Acad Sci USA 2000;97:8386-8391.

43 Tian H, McKnight SL, Russell DW. Endothelial PAS domain protein 1 (EPAS1), a transcription factor selectively expressed in endothelial cells. Genes Dev 1997;11:72-82.

44 Willam C, Koehne P, Jurgensen JS, et al. Tie2 receptor expression is stimulated by hypoxia and proinflamma- tory cytokines in human endothelial cells. Circ Res 2000;87:370-377.

45 Kappel A, Ronicke V, Damert A, et al. Identification of vascular endothelial growth factor (VEGF) receptor-2 (Flk-1) promoter/enhancer sequences sufficient for angioblast and endothelial cell-specific transcription in transgenic mice. Blood 1999;93:4284-4292.

46 Elvert G, Kappel A, Heidenreich R, et al. Cooperative interaction of hypoxia-inducible factor-2alpha (HIF2alpha) and Ets-1 in the transcriptional activation of vascular endothelial growth factor receptor-2 (Flk-1). J Biol Chem 2003;278:7520-7530.

47 Piret JP, Mottet D, Raes M, et al. Is HIF-1alpha a pro- or an anti-apoptotic protein? Biochem Pharmacol 2002; 64:889-892.

48 Vesey DA, Cheung C, Pat B, et al. Erythropoietin protects against ischaemic acute renal injury. Nephrol Dial Transplant 2004;19:348-355.

49 Kanellis J, Fraser S, Katerelos M, et al. Vascular endothelial growth factor is a survival factor for renal tubular epithelial cells. Am J Physiol Renal Physiol 2000;278:F905-F915.

50 Griffin KA, Picken MM, Bidani AK. Blood pressure liability and glomerulosclerosis after normotensive 5/6 renal mass reduction in the rat. Kidney Int 2004;65: 209-218.

51 Bidani AK, Griffin KA, Bakris G, et al. Lack of evidence of blood pressure-independent protection by reninangiotensin system blockade after renal ablation. Kidney Int 2000;57:1651-1661.

52 Sugimoto H, Hamano Y, Charytan D, et al. Neutralization of circulating vascular endothelial growth factor (VEGF) by anti-VEGF antibodies and soluble VEGF receptor 1 (sFlt-1) induces proteinuria. J Biol Chem 2003;278:12605-12608.

53 Foster RR, Hole R, Anderson K, et al. Functional evidence that vascular endothelial growth factor may act as an autocrine factor on human podocytes. Am J Physiol Renal Physiol 2003;284:F1263-F1273.

54 Jacobson HR. Chronic renal failure: pathophysiology. Lancet 1991;338:419-423.

55 Warnecke C, Griethe W, Weidemann A, et al. Activation of the hypoxia-inducible factor-pathway and stimulation of angiogenesis by application of prolyl hydroxylase inhibitors. FASEB J 2003;17:1186-1188.

56 Ivan M, Haberberger T, Gervasi DC, et al. Biochemical purification and pharmacological inhibition of a mammalian prolyl hydroxylase acting on hypoxiainducible factor. Proc Natl Acad Sci USA 2002;99: 13459-13464. 